\title{
Nail Scissor as a Rare Foreign Body in the Urethra: Case Report
}

\author{
Betul Cam ${ }^{1}$, Hakan Tuncer ${ }^{1}$, Ozlem Uzun ${ }^{1}$, Emin Uysal ${ }^{1}$ \\ 1. Emergency Medicine, Bagcilar Education and Research Hospital, Istanbul, TUR
}

Corresponding author: Betul Cam, mbetulcam@gmail.com

\begin{abstract}
Foreign bodies in the urethra are rare in the literature. A majority of the foreign bodies administered in the urethra are because of a psychiatric disorder, senility, intoxication, and self-erotic stimulation. Clinical examination and imaging tests, such as X-ray, ultrasound, computed tomography (CT), and magnetic resonance imaging (MRI) have been used for the diagnosis of foreign bodies. Surgical exploration or endoscopic extraction are the main approaches to the treatment. This case report deals with a 45 -year-old male patient who was admitted with urethral pain to the emergency service. A nail scissor was diagnosed in the urethra and endoscopic extraction was performed under regional anesthesia.

Categories: Emergency Medicine, Radiology, Urology

Keywords: foreign body, self-applied nail scissor., urethra

\section{Introduction}

Foreign bodies can be diagnosed incidentally or while seeking the origin of discomfort related to an inserted body [1]. A foreign body in the lower urinary tract has been reported rarely in the literature [2]. Several cases of the insertion of foreign bodies, such as pins, electrical wires, screws, seeds of olives, or ballpoint pens, have been reported previously [3-7]. Imaging tests help clinicians diagnose many foreign objects in the human body [8-9]. Most patients come to the hospital with diverse complaints, such as hematuria, dysuria, urinary frequency, strangury, and urinary retention [1-7]. The majority of foreign bodies in the lower urinary tract have been administered because of a psychiatric disorder, senility, intoxication, and self-erotic stimulation [2]. Patients have been found commonly in the adult male population. We report a single case of a 45 -year old male patient who inserted a nail scissor in his urethra. He was admitted to hospital with urethral discomfort and pain.
\end{abstract}

Received 10/18/2018

Review began 10/23/2018 Review ended 01/04/2019 Published 01/08/2019

๑) Copyright 2019

Cam et al. This is an open access article distributed under the terms of the Creative Commons Attribution License CC-BY 3.0., which permits unrestricted use, distribution, and reproduction in any medium, provided the original author and source are credited.

\section{Case Presentation}

A 45-year-old male patient applied to the emergency service with a nail scissor inserted in the urethra. The patient gave a history of self-insertion of the instrument in the urethra. There were urethral bleeding and pain with the normal passage of urine. A hard-edged foreign body was pulped by urethral examination. A radiographic image was taken (Figure 1 ) and a nail scissor was diagnosed in the urethra. Urethral extraction was applied under local anesthesia to remove the foreign body (Figure 2). An image could not be taken during the operation because the patient disapproved. Antibiotherapy and analgesia were given to the patient following surgery. The next appointment was set to check for urethral healing in the urology department. 


\section{Cureus}

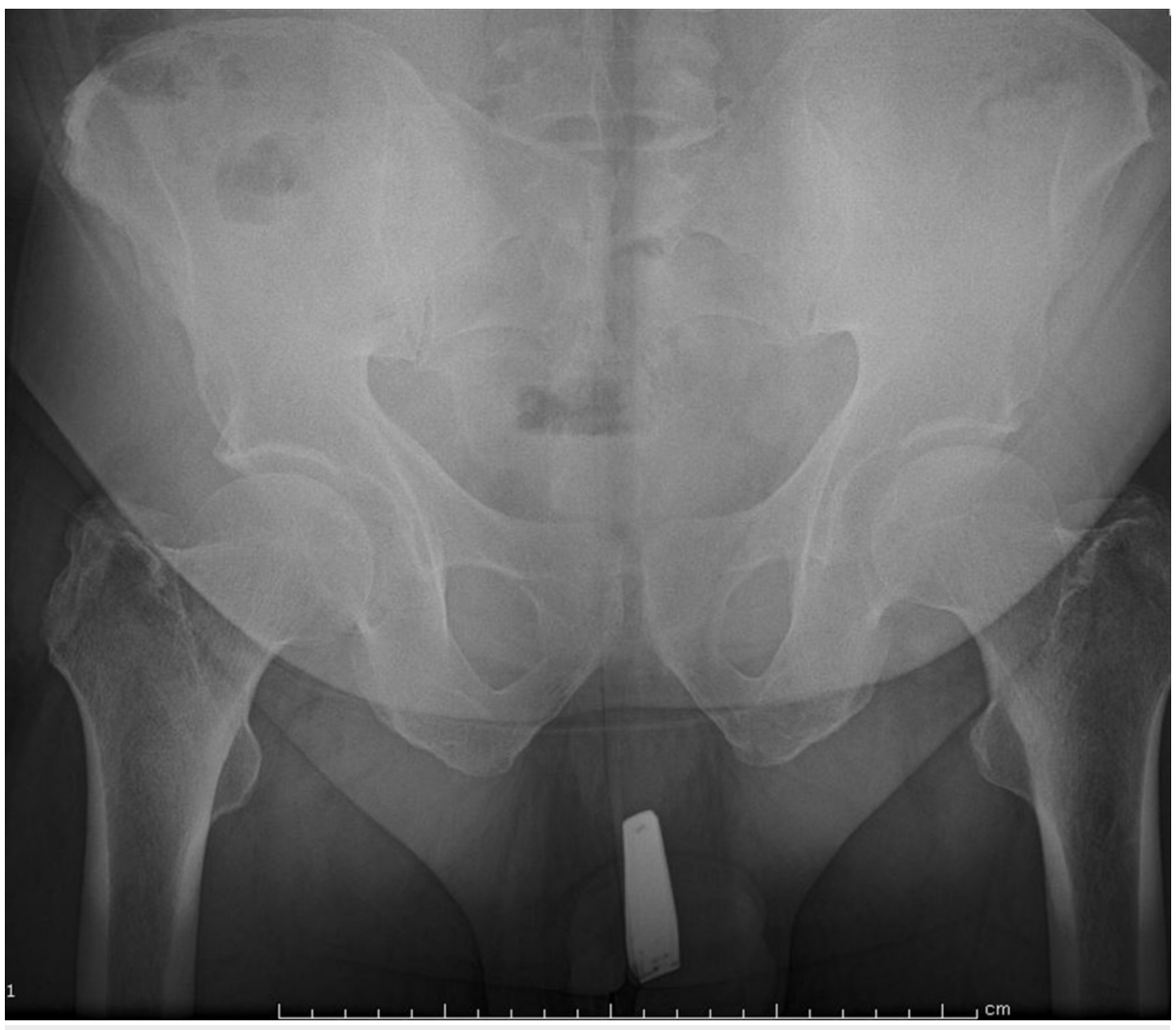

FIGURE 1: Radiological imaging of foreign body in the urethra.

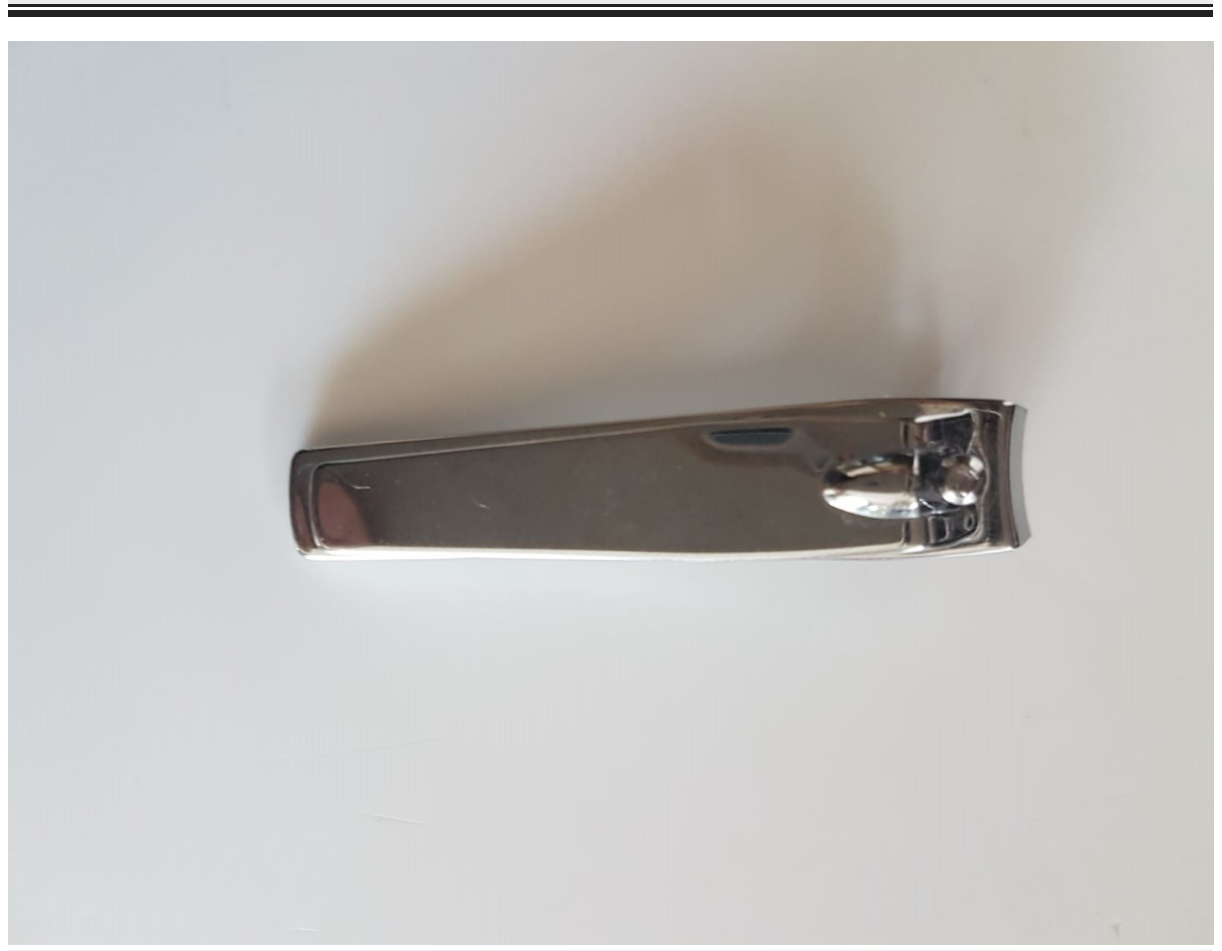

FIGURE 2: Nail scissor removed from the urethra.

\section{Discussion}

Many different foreign bodies have been diagnosed in the male urethra. Self-inserted wires, screws, nuts, a metallic tongue cleaner, and pens have been reported previously [1-7]. Imaging tests, such as X-ray, ultrasound, CT, and MRI, are used to determine the bodies in the genitourinary tract [8-9]. Ultrasound could 
be preferred since it is a cheaper, readily available, and non-invasive technique in the emergency department [8]. The endoscopic and surgical interventions are used for the removal of foreign bodies [10-13]. An endoscopic procedure under local anesthesia is a fast and recommended method for removing foreign bodies, such as wires, pins, screws, and pens, from the urethra. Surgical intervention may also be required in some cases for irregularly shaped large bodies, such as a metallic tongue cleaner, pens, or keys. The following is the extraction antibiotic treatment needed. Psychiatric disorders should be sought in cases of habitual recurrence [14]. A nail scissor is a very rare case in the urethra (Figure 1). The forcing of a nail scissor into the urethra could be harmful due to its hard edges and sharpened side. In this case, a sharp-sided object was removed under local anesthesia, as shown in Figure 2.

\section{Conclusions}

In conclusion, self-applied urethral foreign body insertion is a rare case. Imaging tests are needed for determining the urethral location, shape, and size of the bodies. Urethral stricture might be taken into account after any surgical intervention despite the removal of the foreign body with little damage. Finally, psychiatric counseling should be recommended for these patients.

\section{Additional Information \\ Disclosures}

Human subjects: Consent was obtained by all participants in this study. Conflicts of interest: In compliance with the ICMJE uniform disclosure form, all authors declare the following: Payment/services info: All authors have declared that no financial support was received from any organization for the submitted work. Financial relationships: All authors have declared that they have no financial relationships at present or within the previous three years with any organizations that might have an interest in the submitted work. Other relationships: All authors have declared that there are no other relationships or activities that could appear to have influenced the submitted work.

\section{References}

1. Aliabadi H, Cass AS, Gleich P, Johnson CF: Self-inflicted foreign bodies involving the lower urinary tract and male genitalia. Urology. 1985, 26:12-16.

2. Mahadevappa N, Kochhar G, Vilvapathy KS, Dharwadkar S, Kumar S: Self-inflicted foreign bodies in lower genitourinary tract in males: our experience and review of literature. Urol Ann. 2016, 8:338-342. 10.4103/0974-7796.184904

3. Mitterberger M, Peschel R, Frauscher F, Pinggera GM: Allen key completely in male urethra: a case report . Cases J. 2009, 2:7408. 10.4076/1757-1626-2-7408

4. Dinesh A, Singh A, Neogi S: Tongue cleaner an unusual foreign body in the urethra: a case report . Australas Med J. 2013, 6:508-510.

5. Trehan RK, Haroon A, Memon S, Turner D: Successful removal of a telephone cable, a foreign body through the urethra into the bladder: a case report. J Med Case Rep. 2007, 1:153. 10.1186/1752-1947-1-153

6. Bayraktar Z, Albayrak S: A self-inflicted male urethral/vesical foreign body (olive seed) causing complete urinary retention. Urol Case Rep. 2018, 16:83-85. 10.1016/j.eucr.2017.11.023

7. Higa K, Irving S, Cervantes RJ, Pangilinan J, Slykhouse LR, Woolridge DP, Amini R: The case of an obstructed stone at the distal urethra. Cureus. 2017, 9:e1974. 10.7759/cureus.1974

8. Gupta N, Goyal P, Sharma K, et al.: Penile fracture role of ultrasound. Transl Androl Urol. 2017, 6:580-584. 10.21037/tau.2017.03.38

9. Barzilai M, Cohen I, Stein A: Sonographic detection of a foreign body in the urethra and urinary bladder . Urol Int. 2000, 64:178-180. 10.1159/000030524

10. Rahman NU, Elliott SP, McAninch JW: Self-inflicted male urethral foreign body insertion: endoscopic management and complications. BJU Int. 2004, 94:1051-3. 10.1111/j.1464-410X.2004.05103.x

11. Van Ophoven A, deKernion JB: Clinical management of foreign bodies of the genitourinary tract. J Urol. 2000, 164:274-287.

12. Park S, Moon KH, Kim SH, Kim DY, Cho YW, Cho SJ, Park S: Needles as urethral foreign body in a child: successful removal using a new method with a laparoscopic needle holder. Urology. 2013, 81:188-190. 10.1016/j.urology.2012.09.005

13. Padmanabhan P, Hutchinson RC, Reynolds WS, Kaufman M, Scarpero HM, Dmochowski RR: Approach to management of iatrogenic foreign bodies of the lower urinary tract following reconstructive pelvic surgery. J Urol. 2012, 187:1685-1690. 10.1016/j.juro.2011.12.081

14. Kenney RD: Adolescent males who insert genitourinary foreign bodies: is psychiatric referral required? . Urology. 1988, 32:127-129. 